\section{BMJ Paediatrics Open}

\title{
Early impact of COVID-19 pandemic on paediatric surgical practice in Nigeria: a national survey of paediatric surgeons
}

\author{
Ibukunolu Olufemi Ogundele (D) ," Felix M Alakaloko (D) , ${ }^{2}$ Collins C Nwokoro, ${ }^{1}$ \\ Emmanuel A Ameh (i) ${ }^{3}$
}

To cite: Ogundele I0, Alakaloko FM, Nwokoro CC, et al. Early impact of COVID-19 pandemic on paediatric surgical practice in Nigeria: a national survey of paediatric surgeons. BMJ Paediatrics Open 2020;4:e000732. doi:10.1136/ bmjpo-2020-000732

- Additional material is published online only. To view, please visit the journal online (http://dx.doi.org/10.1136/ bmjpo-2020-000732).

Received 16 May 2020 Revised 27 July 2020 Accepted 4 August 2020
Check for updates

(C) Author(s) (or their employer(s)) 2020. Re-use permitted under CC BY-NC. No commercial re-use. See rights and permissions. Published by BMJ.

${ }^{1}$ Surgery, Olabisi Onabanjo University Teaching Hospital, Sagamu, Ogun, Nigeria ${ }^{2}$ Surgery, Lagos University Teaching Hospital, Surulere, Lagos, Nigeria

${ }^{3}$ Surgery, National Hospital Abuja, Abuja, Federal Capital Territory, Nigeria

Correspondence to Dr Ibukunolu Olufemi Ogundele; ogundeleibk@gmail.com

\section{ABSTRACT}

Introduction The novel coronavirus disease has had significant impact on healthcare globally. Knowledge of this virus is evolving, definitive care is not yet known and mortality is increasing. We assessed its initial impact on paediatric surgical practice in Nigeria, creating a benchmark for recommendations and future reference. Methods Survey of 120 paediatric surgeons from 50 centres to assess sociodemographics and specific domains of impact of COVID-19 on their services and training in Nigeria. Valid responses were represented as categorical data and presented in percentages. Duplicate submissions for centres were excluded by combining and taking the mean of responses from centres with multiple respondents.

Results Response rate was 74 (61\%). Forty-six (92\%) centres had suspended elective surgeries. All centres continued emergency surgeries but volume reduced in March by 31\%. Eleven (22\%) centres reported 13 suspended elective cases presenting as emergencies in March, accounting for $3 \%$ of total emergency surgeries. Twelve (24\%) centres adopted new modalities for managing selected surgical conditions: non-operative reduction of intussusception in $1(2 \%)$, antibiotic management of uncomplicated acute appendicitis in 5 $(10 \%)$ and more conservative management of trauma and replacement of laparoscopic appendectomy with open surgery in $3(6 \%)$, respectively. Low perception of adequacy of personal protective equipment (PPE) was reported in $35(70 \%)$ centres. Forty $(80 \%)$ centres did not offer telemedicine for patients' follow-up. Twentynine (58\%) centres had suspended academic training. Perception of safety to operate was low in $37(50 \%)$ respondents, indifferent in $24 \%$ and high in $26 \%$.

Conclusion Majority of paediatric surgical centres reported cessation of elective surgeries while continuing emergencies. There was, however, an acute decline in the volume of emergency surgeries. Adequate PPE needs to be provided and preparations towards handling backlog of elective surgeries once the pandemic recedes. Further study is planned to more conclusively understand the full impact of this pandemic on children's surgery.

\section{BACKGROUND}

COVID-19 is a highly transmissible novel viral illness caused by SARS-CoV-2. ${ }^{1}$ It was reported to have emerged in Wuhan, China,

\section{What is known about the subject?}

Anecdotal evidence suggests that elective surgeries in children have been suspended due to COVID-19 pandemic.

- Impact of the pandemic on other aspects of management of children with surgical conditions was unclear.

\section{What this study adds}

Most centres (92\%) had suspended elective surgeries.

- Some suspended elective cases developed emergent problems and presented as emergencies, whereas emergency surgeries were impacted with overall reduction from pre-COVID volumes by onethird in March 2020.

- One-fifth of centres for the first time adopted nonoperative modalities of treatment for selected emergent conditions.

in December 2019 but later spread to other parts of China and other countries of the world. ${ }^{2}$ This disease poses a huge challenge to healthcare systems around the world. The US Department of Health and Human Services stated in its 2017 Pandemic Influenza Plan update that 'emerging viral pandemics can place extraordinary and sustained demands on public health and health systems and on providers of essential community services'. The effect may be more profound in regions with already limited resources and fragile health infrastructure. The aim of this study was to carry out a survey of paediatric surgeons in a resource-limited setting to assess early effects of the COVID-19 pandemic on their practice in the initial stages of the outbreak. Data obtained would be used for recommendations and future reference. 


\section{METHODS}

Relevant information was obtained from paediatric surgeons (consultants and senior registrars) currently practising in Nigeria using a pretested questionnaire (online supplementary appendix 1) designed on Microsoft Word V.10 (Microsoft, Seattle, WA, USA) and transcribed to Google form. The questions were based on fivepoint Likert scale (strongly agree, agree, neither agree nor disagree, disagree, strongly disagree). We circulated the forms to the predetermined group of specialists by email and online chat rooms and kept them open from 10 to 17 April 2020. Daily reminders were also sent.

Participants were required to provide sociodemographic data, information on patient traffic and decision on management of specific conditions, availability of personal protective equipment (PPE), impact on surgeon's psyche, their academic programmes and institutions' infrastructure.

For the purpose of analysis, the five-point Likert scale was reduced to three points. Strongly agree and agree were merged as agree, neither agree nor disagree was retained as neutral, disagree and strongly disagree were merged as disagree.

Duplicate submissions for centres were excluded by combining and taking the mean of responses from centres with multiple responses.

Responses were analysed using SPSS V.22 and presented as categorical data and percentages.

\section{Patient and public involvement}

This research was done without patient involvement. Patients were not invited to comment on the study design and were not consulted to develop patientrelevant outcomes or interpret the results. Patients were not invited to contribute to the writing or editing of this document for readability or accuracy.

\section{RESULTS}

\section{Demographics}

A total of 120 paediatric surgeons from 50 centres were sent the survey. Eighty-three paediatric surgeons responded but 74 forms were adequately completed resulting in a response rate of $61 \%$. The 74 completed responses represented the 50 centres across the country. Table 1 shows the sociodemographic characteristics of respondents.

\section{Impact on surgeries}

Elective surgeries had been suspended in $46(92 \%)$ centres at the time of this survey. There was a steady decline in the average number of elective surgeries done over 5 months between November 2019 with 993 (25\% of 5 months total) and March 2020 with 420 (10\% of total) cases. Similar trend was observed with emergency surgeries which reduced from 822 (25\% of 5 months total) in November 2019 to 485 (15\% of total) in March

\begin{tabular}{lll}
\hline Table 1 Sociodemographic characteristics of respondents \\
\hline Characteristics of respondents & Scores & Percentage \\
\hline Cadre & $\mathrm{n}=74$ & \\
\hline Consultant & 45 & 61 \\
\hline Senior registrar & 29 & 39 \\
Gender & $\mathrm{n}=74$ & \\
\hline Male & 62 & 84 \\
\hline Female & 12 & 16 \\
Workplace & $\mathrm{n}=50$ & \\
\hline Public & 48 & 96 \\
\hline Private & 2 & 4 \\
\hline Type of health facility & $\mathrm{n}=50$ & \\
\hline Teaching hospital & 39 & 78 \\
\hline Federal medical centre & 10 & 20 \\
\hline General/specialist hospital & 1 & 2 \\
\hline
\end{tabular}

2020. Comparatively, there were more elective than emergency surgeries per month until March (figure 1).

Twenty (40\%) centres suspended their elective surgeries less than 2 weeks prior to the survey in April, 26 $(52 \%)$ centres stopped a month earlier and $4(8 \%)$ had suspended their elective list for over a month.

\section{Adverse clinical outcomes}

Eleven (22\%) centres reported at least one of the elective cases suspended due to COVID-19 pandemic presenting as emergency in March. There were 13 of such patients accounting for an estimated 3\% of the total emergency surgeries for the month. They included inguinoscrotal hernias $^{4}$ with obstruction, subacute appendicitis ${ }^{2}$ and previously decompressing anovestibular fistula with intestinal obstruction. ${ }^{1}$

\section{Changes in management modality}

Nine $(18 \%)$ centres have newly adopted non-operative modalities for managing selected surgical conditions in response to the pandemic. One (2\%) centre adopted non-operative reduction of intussusception while 5 $(10 \%)$ centres adopted management of uncomplicated acute appendicitis with antibiotics and $3(6 \%)$ took a more conservative approach to management of trauma. Three (6\%) centres replaced laparoscopic appendectomy with open surgery.

The protocol for the management of urgent cases such as cancers and symptomatic hernias in the early period of COVID-19 was to continue to immediately operate in $31(62 \%)$ centres, delayed intervention in $12(24 \%)$, watchful waiting in $2(4 \%)$ and follow-up in $5(10 \%)$.

\section{Impact on surgeons}

Paediatric surgeons' perception of safety to operate during the pandemic and their willingness to operate on patients who are COVID-19 positive are shown in figure 2. Perception of safety to operate rated low in half 


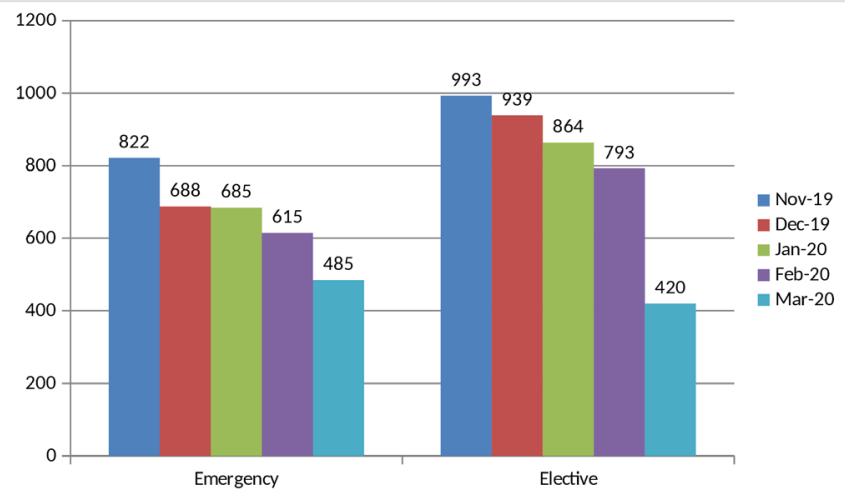

Figure 1 Cluster bar chart of the mean number of surgeries over 5 months.

of respondents. No member of the surgical teams had tested positive for COVID-19 at the time of the survey.

Fifty-seven (77\%) agreed to a need for paediatric surgeons to have additional training in management of surgical patients during epidemics, $6(8 \%)$ were neutral, while $11(15 \%)$ disagreed. Those willing to attend such training were $47(64 \%), 15$ (20\%) were neutral and 12 (16\%) were unwilling.

\section{Impact on institutions, supplies and outpatient clinics}

Forty-two $(84 \%)$ centres had designated isolation wards but only $2(4 \%)$ had COVID-19-positive children on admission and none had managed COVID-19-positive children with surgical conditions in their facility at the time of this survey. Majority of centres had low perception of adequacy of PPE for theatre staff both at the time of survey and at 3 months afterwards as depicted in figure 3. Ratings of how institutions are coping with the COVID-19 pandemic were low in $33(66 \%)$, intermediate in $14(28 \%)$ and high in $3(6 \%)$ centres. Forty $(80 \%)$ centres do not offer hospital-powered telemedicine services for patients' follow-up despite lockdown on outpatient clinics.

\section{Impact on academic training programmes}

Twenty-nine (58\%) centres had suspended academic training during the pandemic, $13(26 \%)$ engaged 'WhatsApp' chat rooms, while $3(6 \%)$ made use of videoconferencing and $5(10 \%)$ still carried out their

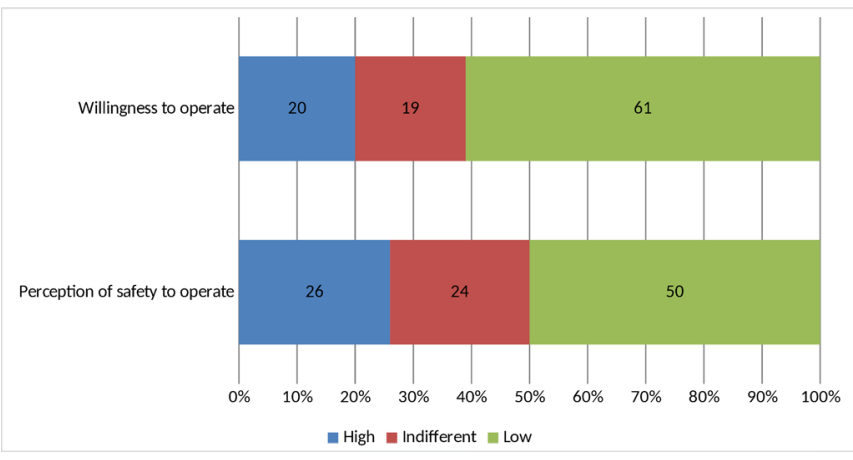

Figure 2 Perception of safety of paediatric surgeons and willingness to operate.

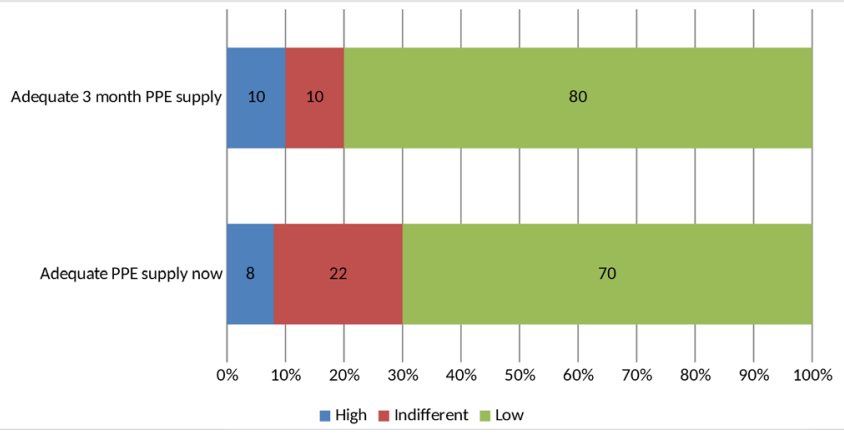

Figure 3 Perception of adequacy of personal protective equipment (PPE) for theatre staff now and in 3 months.

academic training through physical meetings but with social distancing.

\section{DISCUSSION}

Pandemics usually run ravaging courses with unpredictable health, social and economic disruptions. ${ }^{5}$ The impact can be difficult to assess and is an area of active research. While the direct health impact of pandemics can be catastrophic, the indirect impact driven by depletion of resources and reduced access to routine care can lead to further increase in morbidity and mortality. ${ }^{5}$

COVID-19 pandemic is rapidly evolving with unprecedented impact on global health systems. China, and later the USA, Italy and other European countries, became hot spots for the virus after reporting their first cases in December 2019 and January 2020, respectively. ${ }^{267}$ Travellers from these regions brought in the disease to Africa, including Nigeria in February $2020^{89}$ with a rapid expansion in the number of cases in sub-Saharan Africa. ${ }^{10}$ The WHO formally declared COVID-19 outbreak a pandemic on 11 March with 634813 total confirmed cases as of 29 March 2020. ${ }^{411}$ This has sparked various adaptations in healthcare responses and management, with unpredictable outcomes heightened by depletion of resources. For example, the only paediatric surgery care facility in Liberia run by Médecins Sans Frontières has been temporarily suspended due to travel restrictions. ${ }^{12}$

Children are more susceptible to viral respiratory diseases but ironically, statistics on COVID-19 have shown low incidence in this age group. An analysis of 72314 cases of COVID-19 from the Chinese Centre for Disease Control and Prevention showed a low incidence in children with those younger than 10 years accounting for only $1 \%$ of cases. ${ }^{13}$ A recent observational cohort study of 36 children with COVID-19 found that all the patients had mild $(47 \%)$ or moderate $(53 \%)$ types of COVID-19 with a large proportion (28\%) being asymptomatic. ${ }^{14}$ Thus, it was initially thought that this clinical pattern of COVID-19 in the paediatric population could make children important facilitators of viral transmission, and may thus place providers of healthcare in them at increased risk of infection. ${ }^{14-16}$ 
Our survey showed that majority of the paediatric surgeons have stopped operating on all elective conditions in both public and private tertiary health institutions to minimise contact with potential carriers of the virus and conserve resources. This is consistent with the American College of Surgeons (ACS) COVID-19: Elective Case Triage Guidelines for Surgical Care which recommended that surgery should be performed only if delaying the procedure is likely to prolong hospital stay, increase the likelihood of later hospital admission or cause harm to the patient. ${ }^{17}$ A recent article recognises the higher frequency of highly symptomatic patients on the elective operation list in low and middle-income countries (LMICs) compared with high-income countries but still advocates that truly elective operations should be postponed to preserve PPE, staff and facility capacity as important resources during a surge response. ${ }^{18}$

The ACS advocates that "children who have failed attempts at medical management of a surgical condition should be considered for surgery'. ${ }^{17}$ Our study revealed an increased uptake of non-operative management of some surgical conditions such as intussusception, uncomplicated appendicitis and some cases of trauma. This modality of care was probably adopted to reduce exposure to surgery during the pandemic. Outcome of these modifications in management protocol may be subject to future research.

Some suspended elective cases had presented as emergencies. They included incarcerated inguinoscrotal hernias, subacute appendicitis and previously decompressing anovestibular fistula that developed partial obstruction. There is also potential of poorer outcomes for patients with cancer and other urgent cases that have been cancelled but may not necessarily return as emergency. The effect of delay on the outcomes for these patients may not be recognised until a later date (or at all if they die without reaccessing paediatric surgical care at the tertiary hospitals). These are indirect impacts of the pandemic due to reduced access to routine care. Official telemedicine platforms for follow-up care of patients may aid early detection of complications or other needs for hospital visits while elective surgeries remain suspended, outpatient clinics locked down and patients are being given long appointments. Few centres in our survey have an official telemedicine platform for follow-up care of patients especially during this period of COVID-19 pandemic. The ACS recommends that telemedicine and teleconsult services should be used for patient and physician interaction when available. ${ }^{19}$ There is an urgent need to upscale telemedicine services and also to develop protocols for handling backlog of elective surgeries in children in LMICs once the pandemic recedes.

In this report, all centres continued to operate on emergencies and there was consistent monthly average number of surgeries from November 2019 to February 2020 but a sharp decline in March 2020. This corresponded with the period of social and economic disruptions which followed the first confirmed case of
COVID-19 in Nigeria reported on 27 February 2020. ${ }^{9} 20$ These data show the need to adopt consensus guidelines tailored to maintain emergency services in LMICs during this pandemic. Follow-up studies may also evaluate the case mix of emergency surgeries during the period of decline and determine if certain categories of diseases were more affected than others, for example, neonates with congenital anomalies are more likely to be dying in the community as a result of reduced access to paediatric surgical care during the pandemic.

Majority of centres had designated isolation wards, but only $4 \%$ of them had children with the virus and none had managed a COVID-19-positive child with surgical condition. Although local statistics of incidence in children was not available in our literature search, our finding is suggestive of a low incidence of confirmed COVID-19 in children in Nigeria which is consistent with global data. ${ }^{1321}$ Despite this low incidence in children, about half of paediatric surgeons in our survey feel unsafe operating on patients during this period and more are unwilling to operate on confirmed patients with COVID-19. This may be based on the perceived higher risk of transmissibility of the virus from children to healthcare workers. ${ }^{14-16}$ More recent review articles have however refuted this perception with findings that children are not more likely than adults to spread the virus. ${ }^{22}{ }^{23}$ Also, no paediatric surgeon tested positive to COVID-19 at the time of this survey. Although anecdotal evidence is that no surgeon had been tested at the time of our survey, as our National Centre for Disease Control guideline is to test symptomatic individuals and close contacts of confirmed patients. ${ }^{24}$

Majority of centres had suspended academic training during this pandemic. Very few made use of videoconferencing. Poor internet connectivity and high cost of subscription in sub-Saharan Africa may be partly responsible for this poor uptake of video communication. ${ }^{25} 26$ Online chat rooms are generally accessible and may be explored as viable media alternatives.

This research is survey based with attendant limitation of recall. Information obtained is opinion of the surgeons and does not necessarily represent best practices. Only surgeons were interviewed since the teams in all the centres studied were led by surgeons and we felt their opinions would be representative in this early survey. The actual numbers of operations cancelled could not be ascertained in the present study. We shall however include anaesthetists, nurses and other colleagues and attempt to determine the actual numbers of operations cancelled in our follow-up study. Contraction of the Likert scale to three points to simplify the results for analysis may have led to some inaccuracy. The study however does provide information on early impact of COVID-19 pandemic on paediatric surgery in Nigeria to help in beginning to plan towards restarting services and handling future unprecedented situations.

\section{CONCLUSION}

The COVID-19 pandemic has resulted in cessation of elective surgeries and a sharp decline in the number of 
emergency surgeries performed on children in Nigeria. It is crucial that plans begin on how to handle the backlog of surgeries that would have been created. This may well be institution specific but adequate PPE needs to be provided to ensure safety of providers. Further, electronic communication with patients and professional colleagues during the pandemic may help improve the surgical care of children. A follow-up study is planned to identify further impacts of the pandemic on children's surgical care.

\section{Twitter Ibukunolu Olufemi Ogundele @docibkint}

Contributors 100 and FMA conceived the research idea. I00, FMA and CCN conducted the survey. 100, FMA and EAA made the drafts of the manuscript. All the authors made substantive contributions to the intellectual content and reporting of the work described in this article. They all read and approved the final manuscript. 100 and FMA are responsible for the overall content as guarantors.

Funding The authors have not declared a specific grant for this research from any funding agency in the public, commercial or not-for-profit sectors.

Competing interests None declared.

Patient and public involvement Patients and/or the public were not involved in the design, or conduct, or reporting, or dissemination plans of this research.

Patient consent for publication Not required.

Ethics approval Obtained from the Health Research Ethics Committee of Olabisi Onabanjo University Teaching Hospital, Sagamu, Ogun State, Nigeria (00UTH/ HREC/339/2020AP).

Provenance and peer review Not commissioned; externally peer reviewed.

Data availability statement Data are available upon reasonable request. All data relevant to the study are included in the article or uploaded as supplementary information. Raw data from the survey are also available upon reasonable request.

Open access This is an open access article distributed in accordance with the Creative Commons Attribution Non Commercial (CC BY-NC 4.0) license, which permits others to distribute, remix, adapt, build upon this work non-commercially, and license their derivative works on different terms, provided the original work is properly cited, appropriate credit is given, any changes made indicated, and the use is non-commercial. See: http://creativecommons.org/licenses/by-nc/4.0/.

ORCID iDs

Ibukunolu Olufemi Ogundele http://orcid.org/0000-0002-0506-2302

Felix M Alakaloko http://orcid.org/0000-0001-8436-6285

Emmanuel A Ameh http://orcid.org/0000-0003-2386-3039

\section{REFERENCES}

1 Lai C-C, Shih T-P, Ko W-C, et al. Severe acute respiratory syndrome coronavirus 2 (SARS-CoV-2) and coronavirus disease-2019 (COVID-19): the epidemic and the challenges. Int $J$ Antimicrob Agents 2020;55:105924.

2 Shereen MA, Khan S, Kazmi A, et al. COVID-19 infection: origin, transmission, and characteristics of human coronaviruses. $J$ Adv Res 2020;24:91-8.

3 U.S. Department of Health and Human Services. Pandemic Influenza Plan. 2017 Update [Internet].

4 World Health Organization. WHO Director-General's opening remarks at the media briefing on COVID-19. WHO Director General's speeches [Internet, 2020: 4. https://www.who.int/dg/speeches/ detail/who-director-general-s-opening-remarks-at-the-mediabriefing-on-covid-19-11-march-2020

5 Madhav N, Oppenheim B, Gallivan M, et al. Chapter 17: Pandemics: risks, impacts, and mitigation. In: Jamison DT, Gelband H, Horton S, et al, eds. Disease control priorities: improving health and reducing poverty. 3rd edn. Washington, DC: The International Bank for Reconstruction and Development / The World Bank, 2017. https:// www.ncbi.nlm.nih.gov/books/NBK525302/

6 Wang C, Horby PW, Hayden FG, et al. A novel coronavirus outbreak of global health concern. Lancet 2020;395:470-3.

7 Chiara Severgnini e Redazione Online. Coronavirus, primi due casi in Italia: sono due turisti cinesi - Corriere.it [Internet]. Available: https:// www.corriere.it/cronache/20_gennaio_30/coronavirus-italia-corona9d6dc436-4343-11ea-bdc8-faf1f56f19b7.shtml?refresh ce-cp

8 World Health Organization. COVID-19 cases top 10000 in Africa WHO _ Regional Office for Africa. [Internet].

9 Adepoju P. Nigeria responds to COVID-19; first case detected in sub-Saharan Africa. Nat Med 2020;26:444-8.

10 Martinez-Alvarez M, Jarde A, Usuf E, et al. COVID-19 pandemic in West Africa. Lancet Glob Health 2020;8:e631-2.

11 World Health Organization. Mariana N (2020) coronavirus disease 2019 (COVID-19) situation report 69, 2019.

12 COVID-19 Interrupts the Only Pediatric Surgery Care in Liberia Doctors Without Borders - USA.

13 Zunyou W, Jennifer M. Characteristics of and important lessons from the coronavirus disease 2019 (COVID-19) outbreak in China: summary of a report of 72314 cases from the Chinese centre for disease control and prevention. 323, 2020.

14 Qiu H, Wu J, Hong L, et al. Clinical and epidemiological features of 36 children with coronavirus disease 2019 (COVID-19) in Zhejiang, China: an observational cohort study. Lancet Infect Dis 2020;2019:1-8.

15 Kelvin AA, Halperin S. COVID-19 in children : the link in the transmission chain. Lancet Infect Dis 2020;2:2019-20.

16 Fretheim A. The role of children in the transmission of SARSCoV-2 (COVID-19) - a rapid review [Barns rolle $i$ spredning av SARS-CoV-19 (Covid-19) - en hurtigoversikt] Rapid review. Oslo: Folkehelseinstituttet/ Norwegian Institute of Public Health, 2020: 2020. 7-9.

17 American College of Surgeons. COVID 19 : Elective Case Triage Guidelines for Surgical Care. Am Coll Surg 2020;24.

18 Ademuyiwa AO, Bekele A, Berhea AB, et al. COVID-19 preparedness within the surgical, obstetric, and anesthetic ecosystem in subSaharan Africa. Ann Surg 2020;272:e9-13.

19 American College of Surgeons. COVID-19 Guidelines for Triage of Pediatric Patients [Internet]. Available: https://www.facs.org/covid19/clinical-guidance/elective-case/pediatric-surgery

20 Ehanire O. First case of coronavirus disease (Covid-19) confirmed in Nigeria. Nigeria centre for disease control; 2020.

21 She J, Liu L, Liu W. COVID-19 epidemic: disease characteristics in children. J Med Virol 2020;92:747-54.

22 Munro APS, Faust SN. Children are not COVID-19 super spreaders: time to go back to school. Arch Dis Child 2020;105:618-9.

23 Rajmil L. Role of children in the transmission of the COVID-19 pandemic: a rapid scoping review. BMJ Paediatr Open 2020;4:e000722.

24 Federal Ministry of Health. Nigeria Centre for Disease Control. Strategies to Improve Surveillance for COVID-19. Guidance for States [Internet]. Available: https://covid19.ncdc.gov.ng/media/files/ SurveillanceStrategies

25 Akue-Kpakpo A. Study on international Internet connectivity in sub-Saharan Africa. International Telecommunication Union Telecommunication development bureau place des nations $\mathrm{CH}-1211$ Geneva 20 Switzerland, 2013. Available: https://www.itu.int/en/ Pages/default.aspx

26 Concerns over high cost of Internet connection - Punch Newspaper [Internet] 2018:26-7. 